\title{
Molecular mechanisms of docetaxel resistance in prostate cancer
}

\author{
Yohei Sekino, Jun Teishima \\ Department of Urology, Graduate School of Biomedical and Health Sciences, Hiroshima University, Hiroshima 734-8551, Japan. \\ Correspondence to: Dr. Yohei Sekino, Department of Urology, Graduate School of Biomedical and Health Sciences, Hiroshima \\ University, 1-2-3 Kasumi, Minami-ku, Hiroshima 734-8551, Japan. E-mail: akikosekino@gmail.com
} How to cite this article: Sekino Y, Teishima J. Molecular mechanisms of docetaxel resistance in prostate cancer. Cancer Drug
Resist2020;3:676-85. http://dx.doi.org/10.20517/cdr.2020.37

Received: 27 May 2020 First Decision: 3 Jun 2020 Revised: 28 Jun 2020 Accepted: 7 Jul 2020 Available online: 21 Aug 2020

Academic Editor: Vincent C. O. Njar Copy Editor: Cai-Hong Wang Production Editor: Jing Yu

\begin{abstract}
Docetaxel (DTX) chemotherapy offers excellent initial response and confers significant survival benefit in patients with castration-resistant prostate cancer (CRPC). However, the clinical utility of DTX is compromised when primary and acquired resistance are encountered. Therefore, a more thorough understanding of DTX resistance mechanisms may potentially improve survival in patients with CRPC. This review focuses on DTX and discusses its mechanisms of resistance. We outline the involvement of tubulin alterations, androgen receptor (AR) signaling/AR variants, ERG rearrangements, drug efflux/influx, cancer stem cells, centrosome clustering, and phosphoinositide 3-kinase/AKT signaling in mediating DTX resistance. Furthermore, potential biomarkers for DTX treatment and therapeutic strategies to circumvent DTX resistance are reviewed.
\end{abstract}

Keywords: Prostate cancer, docetaxel, drug resistant cancer, biomarker

\section{INTRODUCTION}

Prostate cancer (PCa) is one of the most common malignancies worldwide. In 2018, it was estimated that there were 1,200,000 new cases and 350,000 men died due to $\mathrm{PCa}^{[1]}$. Androgen deprivation therapy (ADT) has been widely utilized as the first-line treatment for $\mathrm{PCa}^{[2]}$. Although ADT is initially effective, PCa may eventually progresses to the life-threatening stage of castration-resistant prostate cancer (CRPC) ${ }^{[3]}$. In 2004, docetaxel (DTX) plus prednisone was approved by the FDA as a first-line treatment for patients with CRPC $^{[4,5]}$. DTX is a cytotoxic chemotherapeutic agent which binds to the $\beta$-tubulin subunit thereby

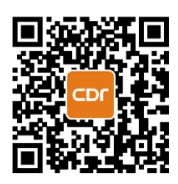


1. Tubulin alterations

The increased expression of $\beta$ III-tubulin leads to DTX resistance. $\beta$ III-tubulin exhibits predictive value for DTX treatment 2. AR and AR-variants ${ }^{[25-30,32-39]}$

AR signaling and AR-variants are involved in DTX resistance. There are conflicting results regarding AR and AR-variants as biomarkers for DTX resistance

3. ERG rearrangement ${ }^{[42-47]}$

Overexpression of ERG induces DTX resistance by altering microtubule dynamics. Serum TMPRSS2-ERG expression has a role in predictive value for DTX treatment

4. Drug efflux and influx ${ }^{[48-50,53-57,60-62]}$

ABCB1 expression is up-regulated in DTX-resistant PCa cell lines. Several drugs targeting ABCB1 enhance DTX efficacy. SLCO1B3 expression is down-regulated in DTX-resistant PCa cell lines

5. Cancer stem cells ${ }^{[64,69-74,76-84]}$

CD44 and CD133 enrich the stem-cell like properties and contribute to DTX resistance in PCa cell lines

6. Centrosome clustering ${ }^{[85,88,89,91,92]}$

KIF11 and KIFC1 interact with microtubules and are involved in DTX resistance

7. PI3K/AKT signal upregulation ${ }^{[96-99]}$

Long-term DTX therapy induces up-regulated pAKT expression. Several drugs targeting AKT/PI3K enhance DTX efficacy

DTX: docetaxel; AR: androgen receptor; PCa: prostate cancer; pAKT: phosphorylated AKT; PI3K: phosphoinositide 3-kinase

preventing depolymerization of the microtubules, leading to mitotic arrest, apoptosis, and inhibition of cellular trafficking ${ }^{[6,7]}$. DTX has also been shown to inhibit androgen receptor (AR) nuclear translocation and the expression of AR in-vitro ${ }^{[8,9]}$. The recent clinical trials of CHAARTED and STAMPEDE have shown that DTX added to ADT treatment significantly improves the overall survival (OS) of patients with metastatic hormone-sensitive $\mathrm{PCa}^{[10,11]}$, indicating that DTX treatment is progressing to becoming crucial in PCa. Nevertheless, despite the prolonged survival resulting from DTX, nearly all patients treated with DTX become refractory due to the development of resistance ${ }^{[12]}$. Therefore, elucidating DTX resistance mechanisms may lead to breakthroughs in CRPC treatment. This review presents molecular mechanisms related to DTX resistance [Table 1], potential biomarkers, and therapeutic strategies to improve survival in CRPC.

\section{MECHANISMS OF RESISTANCE TO DOCETAXEL IN PROSTATE CANCER}

\section{Tubulin alterations}

The active binding site of DTX to microtubules has been actively studied, in order to elucidate the cause of DTX resistance. Microtubules are formed by the polymerization of a dimer of two globular proteins, $\alpha$ and $\beta$ tubulin $^{[13]}$. Although seven different $\beta$-tubulin isotypes exist in humans, the functional significance of these isotypes has not been fully explained ${ }^{[14]}$. Most mutations in the drug-binding sites are thought to mediate resistance by inducing reduced affinity of the drug-tubulin binding ${ }^{[15]}$. One study has shown that a mutation (F270I) in the drug binding sites of the $\beta I$-tubulin gene was discovered in DTX-resistant PCa cell lines, conferring resistance to DTX ${ }^{[16]}$. $\beta$ III-tubulin encoded by the TUBB3 gene is a microtubule protein mainly expressed in neuronal cells ${ }^{[13]}$. Some studies have reported that overexpression of TUBB3 confers DTX resistance in $\mathrm{PCa}^{[17,18]}$. The status of TUBB3 expression has a predictive value for OS in CRPC patients treated with $\mathrm{DTX}^{[17,19]}$. MAPT, which encodes the microtubule-associated protein tau, works in tubulin assembly and microtubule stabilization ${ }^{[20]}$. MAPT expression is upregulated in DTX-resistant PCa cell lines, and subsequent knockdown of MAPT increases the sensitivity of DTX ${ }^{[21]}$. Although these proteins related to microtubules play essential roles in DTX resistance, there has been no effective clinical therapies to target them thus far ${ }^{[22]}$. The formation of microtubule bundling in interphase cells serves as a hallmark of taxane on-target stabilizing activity ${ }^{[23]}$. A recent study showed that loss of microtubule bundling was observed in DTX resistant tumors after DTX treatment using a xenograft model. Notably, despite of the small sample size, the extent of microtubule bundling was associated with DTX response ${ }^{[24]}$. 


\section{AR/AR-variants}

Microtubule stabilization plays an important role in AR cellular transport and nuclear translocation ${ }^{[25]}$. DTX activity may partly disrupt AR nuclear transport and signaling ${ }^{[9,26]}$. These findings suggest that AR signaling is involved in DTX resistance. Indeed, several studies have reported that some molecules promote DTX resistance through the activation of AR signaling ${ }^{[27,28]}$. The predictive value of AR using circulating tumor cells (CTCs) has also been reported ${ }^{[25,29]}$. The recent TAXINERGY clinical trial demonstrated that persistent nuclear AR localization in the CTCs under DTX therapy may serve as a predictive marker of DTX resistance ${ }^{[29]}$. In contrast to these reports, sequence analysis has shown that patients with a gain in plasma AR exhibit a favorable response to DTX ${ }^{[30]}$.

AR variants (AR-v7 and AR-v567es) are unable to bind to the ligand dihydrotestosterone. Therefore, AR variants are constitutively active and act to drive PCa progression through promoting transcription of AR target genes ${ }^{[31]}$. Furthermore, AR variants do not require microtubule-assisted translocation due to the lack of microtubule binding domains ${ }^{[32]}$. Thus, it is rational to expect that AR variants are involved in DTX resistance. Several studies have similarly reported that AR variants confer insensitivity to DTX treatment ${ }^{[32,33]}$. However, evidence for the contribution of AR variants to DTX resistance has not been fully established. Some studies have described that AR-v7 does not induce resistance to DTX ${ }^{[34]}$. Moreover, the expression of AR variants is not upregulated in DTX-resistant PCa cell lines ${ }^{[35,36]}$.

Clinical evidence for the contribution of AR variants to DTX resistance also remains conflicting. Recent studies have shown that the increased expression of AR-v7 is associated with a worse prognosis in CTCs expressed in metastatic CRPC treated with taxanes, including DTX ${ }^{[37,38]}$. On the contrary, another study showed no significant association between AR-v7 expression and the efficacy of DTX in CTCs ${ }^{[39]}$. Of note, recent research has shown that AR-v7 exosomal mRNA as quantified by droplet digital polymerase chain reaction is observed in healthy volunteers ${ }^{[40]}$. The non-specific detection of AR-v7 in blood could help to explain the above-mentioned conflicting evidence on the predictive value of AR-v7 to DTX response ${ }^{[38]}$.

\section{ERG rearrangement}

TMPRSS2-ERG rearrangement is a PCa-specific genetic alteration that leads to overexpression of $\mathrm{ERG}^{[41]}$. A mass spectrometric analysis has shown that the transcription factor ERG directly interacts with $\beta$-tubulin in $\mathrm{PCa}^{[42]}$. A recent study on PCa reported an association between ERG fusion status and high expression of TUBB3, which exists as one of the isotypes of $\beta$-tubulin ${ }^{[43]}$. Overexpression of ERG induced DTX resistance in CRPC patients by altering microtubule dynamics through interaction with $\beta$-tubulin ${ }^{[4]}$. Another recent study found that targeting the TMPRSS2/ERG fusion mRNA using liposomal nano-vectors enhances DTX treatment in $\mathrm{PCa}^{[45]}$. Several studies have reported the possible role of TMPRSS2-ERG expression as a biomarker for DTX response. ERG overexpression has a two-fold increase in the chance of developing DTX resistance as compared to ERG-negative cancers in CTCs from CRPC patients treated with DTX ${ }^{[44]}$. Moreover, TMPRSS2-ERG expression in blood and tumor predicts poor OS in metastatic CRPC patients following DTX ${ }^{[46,47]}$. Thus, assessment of TMPRSS2-ERG expression may be a useful tool when selecting treatment in patients with CRPC.

\section{Docetaxel intracellular accumulation: drug efflux and influx}

DTX binds to free tubulin in the cytoplasm, and an adequate intracellular concentration is vital to stabilize the microtubules ${ }^{[33]}$. The intracellular concentration of DTX depends on the ratio of drug influx and efflux pumps ${ }^{[48]}$. Therefore, downregulation of influx transporter activity or upregulation of efflux transporters activity may play crucial roles in DTX efficacy ${ }^{[49,50]}$.

Efflux transporters activity: ATP-binding cassette $(\mathrm{ABC})$ transporters, which transport various molecules across membranes, are classified into the $\mathrm{ABC}$ superfamily based on the organization of their $\mathrm{ABC}$ 
domains $^{[51]}$. P-glycoprotein/ATP-binding cassette sub-family B member 1 (ABCB1), which is encoded by multidrug-resistance protein 1 , is one of the members of the $\mathrm{ABC}$ transporters ${ }^{[52]}$. $\mathrm{ABCB} 1$ demonstrates high-affinity binding to DTX and can efficiently pump DTX out of treated tumor cells hence decreasing the efficacy of stabilizing microtubules ${ }^{[7,53]}$. An increase in certain variants of ABCB1 expression has been associated with DTX resistance in $\mathrm{PCa}^{[54]}$. Knockdown of $\mathrm{ABCB} 1$ increases sensitivity of PCa cell lines to $\mathrm{DTX}^{[49]}$. A preclinical study showed that $\mathrm{ABCB} 1$ is involved in cross-resistance between DTX and cabazitaxel ${ }^{[55]}$. Several studies have shown the potential of blocking ABCB1 to enhance DTX efficacy through the use of elacridar, BKM1972, enzalutamide, and ROR $\gamma$ antagonist SR2211 ${ }^{[5,56]}$. One study investigated the predictive value of $\mathrm{ABCB} 1$, and found that exosomal $\mathrm{ABCB} 1$ levels are increased in DTXresistant patients as compared to those in therapy-naïve patients with $\mathrm{CRPC}^{[57]}$.

Influx transporter activity: The organic anion transporting polypeptide, which is an SLCO-encoded membrane protein, can transport drugs ${ }^{[58]}$. SLCO1B3 is a known influx transporter of DTX into the cell $^{[59,60]}$. Several studies have shown that SLCO genetic variants (SLCO1B3 and SLCO2B1) are associated with poorer outcomes in $\mathrm{PCa}^{[61,62]}$. The expression of SLCO1B3 was significantly downregulated in a DTXresistant PCa cell line. In addition, overexpression of SLCO1B3 is related to higher intracellular DTX concentrations, suggesting that loss of SLCO1B3 may drive DTX resistance ${ }^{[60]}$.

\section{Cancer stem cells}

Recently, the importance of cancer stem cells (CSCs) has been reported in a wide variety of biological processes relevant to $\mathrm{PCa}^{[63]}$. PCa cells surviving chemotherapy exhibit an increased number of $\mathrm{CSCs}^{\left[{ }^{[6,64]}\right.}$. CD44, CD133, and ALDH have also been associated as biomarkers for CSCs in $\mathrm{PCa}^{[65-68]}$.

CD44: a transmembrane glycoprotein, is a major component of the extracellular matrix and acts as a receptor for several growth factors and cytokines ${ }^{[69]}$. A number of studies have reported that DTX-resistant PCa cell lines are strongly enriched for CD44 expression ${ }^{[69,70]}$. DTX treatment induces a subpopulation of cells which exhibit CD44 upregulation and display enhanced resistance to DTX ${ }^{[7,72]}$. Knockdown of CD44 expression was shown to decrease DTX resistance in PCa cell lines ${ }^{[6]]}$. A recent study showed that CD44 promotes migration and invasion of DTX-resistant PCa cells, possibly through the activation of the Hippo-YAP signaling pathway ${ }^{[69]}$, which is a major player in $\mathrm{CSCs}^{[73]}$. Another recent study showed that an anti-bacterium, salinomycin, can specifically suppress the tumor-initiating cells, which are enriched for CD44 expression in DTX-resistant PCa cells ${ }^{[74]}$.

CD133: a pentaspan transmembrane protein, has been used as a marker for identification of CSCs in $\mathrm{PCa}^{[75]}$. CD133 enriches the stem-cell properties, contributing to DTX resistance in PCa cell lines ${ }^{[76]}$. A recent study showed that the combination of DTX with a nanoplatform targeting CD133 exerts an antitumor effect in a xenograft model ${ }^{[77]}$.

CSC-associated pathways (NOTCH and Hedgehog): Cell lines with DTX resistance display enhanced activity of Notch and Hedgehog signaling ${ }^{[7,78]}$. Knockdown of Notch signaling has been shown to reverse DTX resistance in $\mathrm{PCa}^{[71,79]}$. Furthermore, Notch1 signaling promotes DTX resistance via regulating ABCC1 expression in PCa stem cells ${ }^{[80]}$. Inhibition of EGFR and Hedgehog signaling by gefitinib and cyclopamine improves the efficacy of DTX in PCa cell lines ${ }^{[81,82]}$. Recent studies have shown that the Notch pathway inhibitor PF-03084014 and Hedgehog pathway inhibitor GDC-0449 enhance anti-tumoric effects of DTX on $\mathrm{PCa}^{[83,84]}$.

\section{Centrosome clustering}

Kinesins are motor proteins that hydrolyze ATP and move along microtubule filaments ${ }^{[85]}$. They are involved in several cellular processes, including that of cellular cargo transport and mitosis ${ }^{[86]}$. In addition, 
they have been associated with resistance to DTX treatment in solid tumors, including PCa ${ }^{[85]}$. KIF 11 separates spindle poles of a mitotic cell by moving to the plus-ends of microtubules ${ }^{[87]}$. KIF11 inhibitors such as ispinesib and S-trityl-L-cysteine have anti-tumor activity in DTX-resistant PCa cell lines ${ }^{[88,89]}$. Kinesin family member $\mathrm{C}_{1}$ (KIFC1) is a minus end-directed motor protein that plays an essential role in centrosome clustering ${ }^{[85,90]}$. Previously, we showed that KIFC1 was associated with a poorer prognosis after radical prostatectomy or after DTX treatment in $\mathrm{PCa}^{[91]}$. Furthermore, KIFC1 inhibitor CW069 induces apoptosis and reverses the resistance to DTX in PCa cell lines ${ }^{[92]}$.

\section{PI3K/AKT signaling}

The PI3K/AKT pathway regulates multiple cellular functions through important signaling pathways in cancer $^{[93]}$. The expression of phosphorylated AKT (pAKT) is upregulated in more aggressive subtypes of prostate cancers due to the inactivation of $\mathrm{PTEN}^{[94]}$. AKT has also been directly linked to AR signaling, where the blockade of $\mathrm{AR}$ leads to activation of $\mathrm{AKT}^{[95]}$, indicating that a reciprocal regulation relationship exists between AKT and AR. These findings suggest that the PI3K/AKT pathway may be a promising therapeutic target in CRPC. Furthermore, long-term ADT and DTX induce pAKT expression in patients with $\mathrm{CRPC}^{[96]}$, indicating that the AKT pathway is involved in DTX resistance. Indeed, several studies have shown the potential of AKT/PI3K inhibition in CRPC. In vivo analysis has shown that the dual PI3K/ mTOR inhibitor NVP-BEZ235 sensitizes DTX and has synergistic effect when administered together with DTX in CRPC $^{[97]}$. A further preclinical study has reported that AKT inhibitor AZD5363 has a synergistic effect with DTX in patients with PIK3CA mutation and PTEN mutation ${ }^{[98,99]}$.

\section{Biomarkers to predict docetaxel anti-tumor activity}

As we discover more about DTX resistance, it will become increasingly important to develop novel biomarkers for response to DTX, as well as patient monitoring strategies to stratify patients for treatment.

Circulating tumor cells: CTCs are nucleated tumor cells that are released into the peripheral blood from epithelial tumors ${ }^{[100]}$. The role of CTCs as a prognostic marker in metastatic CRPC patients has been well studied ${ }^{[101]}$. Recent clinical trials have shown that a decrease in CTC count is associated with a favorable outcome in CRPC patients treated with DTX, indicating that the number of CTCs could serve as a prognostic tool for DTX treatment in metastatic $\mathrm{CRPC}^{[102]}$. Another recent trial has shown that the CTC count at the start of DTX therapy is an independent prognostic factor in metastatic CRPC treated with DTX. Patients with a low CTC count exhibit a more favorable outcome than those with a high CTC count $^{[103]}$.

Cell free DNA: Apoptotic cells have the potential to release cell-free fragments of DNA (cfDNA) into the bloodstream ${ }^{[104]}$. A retrospective study has shown that the concentration of cfDNA orior to therapy is an independent prognostic marker for response to DTX in CRPC. Patients with low cfDNA concentration demonstrate a more favorable outcome than those with high cfDNA concentration ${ }^{[105]}$. Further studies have supported the concentration of cfDNA as a predictive biomarker of DTX response. The recent FIRSTANA clinical study has shown that a decline in the concentration of cfDNA during the cycles of taxane including DTX correlated with a favorable response ${ }^{[106]}$. Therefore, cfDNA may be of utility in selecting CRPC patients who may benefit from taxane-based chemotherapy.

\section{CONCLUSION}

Currently, development of resistance to DTX is inevitable in the course of CRPC management. However, several strategies to overcome DTX resistance have been described, and these may improve DTXbased chemotherapy. Further identification of proteins involved in DTX resistance, the establishment of appropriate biomarkers for DTX treatment, and the investigation of therapeutic combination approaches are necessary to prolong patient survival in patients with CRPC. 


\section{DECLARATIONS}

\section{Acknowledgments}

This work was carried out with the kind cooperation of the Research Center for Molecular Medicine of the Faculty of Medicine of Hiroshima University. We also thank the Analysis Center of Life Science of Hiroshima University for the use of their facilities.

\section{Authors' contributions}

Study Design: Sekino Y, Teishima J

Draft the Manuscript: Sekino Y

Edit the Manuscript: Teishima J

Approved the final content for journal submission and publication: Sekino Y, Teishima J

\section{Availability of data and materials}

Not applicable.

\section{Financial support and sponsorship}

None.

\section{Conflicts of interest}

All authors declared that there are no conflicts of interest.

\section{Ethical approval and consent to participate}

Not applicable.

\section{Consent for publication}

Not applicable.

\section{Copyright}

(c) The Author(s) 2020.

\section{REFERENCES}

1. Bray F, Ferlay J, Soerjomataram I, Siegel RL, Torre LA, et al. Global cancer statistics 2018: GLOBOCAN estimates of incidence and mortality worldwide for 36 cancers in 185 countries. CA Cancer J Clin 2018;68:394-424.

2. Cornford P, Bellmunt J, Bolla M, Briers E, De Santis M, et al. EAU-ESTRO-SIOG guidelines on prostate cancer. Part II: treatment of relapsing, metastatic, and castration-resistant prostate cancer. Eur Urol 2017;71:630-42.

3. Karantanos T, Evans CP, Tombal B, Thompson TC, Montironi R, et al. Understanding the mechanisms of androgen deprivation resistance in prostate cancer at the molecular level. Eur Urol 2015;67:470-9.

4. Petrylak DP, Tangen CM, Hussain MH, Lara PN, Jones JA, et al. Docetaxel and estramustine compared with mitoxantrone and prednisone for advanced refractory prostate cancer. N Engl J Med 2004;351:1513-20.

5. Tannock IF, de Wit R, Berry WR, Horti J, Pluzanska A, et al; TAX 327 Investigators. Docetaxel plus prednisone or mitoxantrone plus prednisone for advanced prostate cancer. N Engl J Med 2004;351:1502-12.

6. Kraus LA, Samuel SK, Schmid SM, Dykes DJ, Waud WR, et al. The mechanism of action of docetaxel (Taxotere) in xenograft models is not limited to bcl-2 phosphorylation. Invest New Drugs 2003;21:259-68.

7. Kroon J, Kooijman S, Cho NJ, Storm G, van der Pluijm G. Improving taxane-based chemotherapy in castration-resistant prostate cancer. Trends Pharmacol Sci 2016;37:451-62.

8. Gan L, Chen S, Wang Y, Watahiki A, Bohrer L, et al. Inhibition of the androgen receptor as a novel mechanism of taxol chemotherapy in prostate cancer. Cancer Res 2009;69:8386-94.

9. Mistry SJ, Oh WK. New paradigms in microtubule-mediated endocrine signaling in prostate cancer. Mol Cancer Ther 2013;12:555-66.

10. James ND, Sydes MR, Clarke NW, Mason MD, Dearnaley DP, et al. Addition of docetaxel, zoledronic acid, or both to first-line longterm hormone therapy in prostate cancer (STAMPEDE): survival results from an adaptive, multiarm, multistage, platform randomised controlled trial. Lancet 2016;387:1163-77.

11. Kyriakopoulos CE, Chen YH, Carducci MA, Liu G, Jarrard DF, et al. Chemohormonal therapy in metastatic hormone-sensitive prostate 
cancer: long-term survival analysis of the randomized phase III E3805 CHAARTED trial. J Clin Oncol 2018;36:1080-7.

12. Bumbaca B, Li W. Taxane resistance in castration-resistant prostate cancer: mechanisms and therapeutic strategies. Acta Pharm Sin B 2018;8:518-29.

13. Goodson HV, Jonasson EM. Microtubules and microtubule-associated proteins. Cold Spring Harb Perspect Biol 2018;10:a022608.

14. Lopata MA, Cleveland DW. In vivo microtubules are copolymers of available beta-tubulin isotypes: localization of each of six vertebrate beta-tubulin isotypes using polyclonal antibodies elicited by synthetic peptide antigens. J Cell Biol 1987;105:1707-20.

15. Kanakkanthara A, Eras J, Northcote PT, Cabral F, Miller JH. Resistance to peloruside A and laulimalide: functional significance of acquired $\beta I$-tubulin mutations at sites important for drug-tubulin binding. Curr Cancer Drug Targets 2014;14:79-90.

16. Hara T, Ushio K, Nishiwaki M, Kouno J, Araki H, et al. A mutation in beta-tubulin and a sustained dependence on androgen receptor signalling in a newly established docetaxel-resistant prostate cancer cell line. Cell Biol Int 2010;34:177-84.

17. Ploussard G, Terry S, Maillé P, Allory Y, Sirab N, et al. Class III beta-tubulin expression predicts prostate tumor aggressiveness and patient response to docetaxel-based chemotherapy. Cancer Res 2010;70:9253-64.

18. Sekino Y, Han X, Kawaguchi T, Babasaki T, Goto K, et al. TUBB3 reverses resistance to docetaxel and cabazitaxel in prostate cancer. Int J Mol Sci 2019;20:3936.

19. Maahs L, Sanchez BE, Gupta N, Van Harn M, Barrack ER, et al. Class III $\beta$-tubulin expression as a predictor of docetaxel-resistance in metastatic castration-resistant prostate cancer. PLoS One 2019;14:e0222510.

20. Weingarten MD, Lockwood AH, Hwo SY, Kirschner MW. A protein factor essential for microtubule assembly. Proc Natl Acad Sci U S A 1975;72:1858-62.

21. Yang J, Yu Y, Liu W, Li Z, Wei Z, et al. Microtubule-associated protein tau is associated with the resistance to docetaxel in prostate cancer cell lines. Res Rep Urol 2017;9:71-7.

22. Hotte SJ. Addressing taxane resistance in metastatic castration-resistant prostate cancer: a focus on chaperone proteins. Future Oncol 2017;13:369-79.

23. Yang CH, Horwitz SB. Taxol((R)): the first microtubule stabilizing agent. Int J Mol Sci 2017;18:1733.

24. Gjyrezi A, Xie F, Voznesensky O, Khanna P, Calagua C, et al. Taxane resistance in prostate cancer is mediated by decreased drug-target engagement. J Clin Invest 2020;130:3287-98.

25. Darshan MS, Loftus MS, Thadani-Mulero M, Levy BP, Escuin D, et al. Taxane-induced blockade to nuclear accumulation of the androgen receptor predicts clinical responses in metastatic prostate cancer. Cancer Res 2011;71:6019-29.

26. Kuroda K, Liu H, Kim S, Guo M, Navarro V, et al. Docetaxel down-regulates the expression of androgen receptor and prostate-specific antigen but not prostate-specific membrane antigen in prostate cancer cell lines: implications for PSA surrogacy. Prostate 2009;69:1579-85.

27. Komura K, Jeong SH, Hinohara K, Qu F, Wang X, et al. Resistance to docetaxel in prostate cancer is associated with androgen receptor activation and loss of KDM5D expression. Proc Natl Acad Sci U S A 2016;113:6259-64.

28. Sekino Y, Sakamoto N, Goto K, Honma R, Shigematsu Y, et al. Transcribed ultraconserved region Uc.63+ promotes resistance to docetaxel through regulation of androgen receptor signaling in prostate cancer. Oncotarget 2017;8:94259-70.

29. Antonarakis ES, Tagawa ST, Galletti G, Worroll D, Ballman K, et al; TAXYNERGY Investigators. Randomized, Noncomparative, Phase II Trial of Early Switch From Docetaxel to Cabazitaxel or Vice Versa, With Integrated Biomarker Analysis, in Men With ChemotherapyNaïve, Metastatic, Castration-Resistant Prostate Cancer. J Clin Oncol 2017;35:3181-8.

30. Conteduca V, Jayaram A, Romero-Laorden N, Wetterskog D, Salvi S, et al. Plasma androgen receptor and docetaxel for metastatic castration-resistant prostate cancer. Eur Urol 2019;75:368-73.

31. Hu R, Lu C, Mostaghel EA, Yegnasubramanian S, Gurel M, et al. Distinct transcriptional programs mediated by the ligand-dependent full-length androgen receptor and its splice variants in castration-resistant prostate cancer. Cancer Res 2012;72:3457-62.

32. Zhang G, Liu X, Li J, Ledet E, Alvarez X, et al. Androgen receptor splice variants circumvent AR blockade by microtubule-targeting agents. Oncotarget 2015;6:23358-71.

33. Thadani-Mulero M, Nanus DM, Giannakakou P. Androgen receptor on the move: boarding the microtubule expressway to the nucleus. Cancer Res 2012;72:4611-5.

34. Shimizu Y, Tamada S, Kato M, Hirayama Y, Takeyama Y, et al. Androgen receptor splice variant 7 drives the growth of castration resistant prostate cancer without being involved in the efficacy of taxane chemotherapy. J Clin Med 2018;7:444.

35. Lombard AP, Liu L, Cucchiara V, Liu C, Armstrong CM, et al. Intra versus inter cross-resistance determines treatment sequence between taxane and AR-targeting therapies in advanced prostate cancer. Mol Cancer Ther 2018;17:2197-205.

36. Shiota M, Dejima T, Yamamoto Y, Takeuchi A, Imada K, et al. Collateral resistance to taxanes in enzalutamide-resistant prostate cancer through aberrant androgen receptor and its variants. Cancer Sci 2018;109:3224-34.

37. Tagawa ST, Antonarakis ES, Gjyrezi A, Galletti G, Kim S, et al. Expression of AR-V7 and ARv567es in circulating tumor cells correlates with outcomes to taxane therapy in men with metastatic prostate cancer treated in TAXYNERGY. Clin Cancer Res 2019;25:1880-8.

38. Marín-Aguilera M, Jiménez N, Reig Ò, Montalbo R, Verma AK, et al. Androgen receptor and its splicing variant 7 expression in peripheral blood mononuclear cells and in circulating tumor cells in metastatic castration-resistant prostate cancer. Cells 2020;9:203.

39. Antonarakis ES, Lu C, Luber B, Wang H, Chen Y, et al. Androgen receptor splice variant 7 and efficacy of taxane chemotherapy in patients with metastatic castration-resistant prostate cancer. JAMA Oncol 2015;1:582-91.

40. Nimir M, Ma Y, Jeffreys SA, Opperman T, Young F, et al. Detection of AR-V7 in liquid biopsies of castrate resistant prostate cancer patients: a comparison of AR-V7 analysis in circulating tumor cells, circulating tumor RNA and exosomes. Cells 2019;8:688.

41. Tomlins SA, Rhodes DR, Perner S, Dhanasekaran SM, Mehra R, et al. Recurrent fusion of TMPRSS2 and ETS transcription factor genes in prostate cancer. Science 2005;310:644-8. 
42. Brenner JC, Ateeq B, Li Y, Yocum AK, Cao Q, et al. Mechanistic rationale for inhibition of poly(ADP-ribose) polymerase in ETS gene fusion-positive prostate cancer. Cancer Cell 2011;19:664-78.

43. Tsourlakis MC, Weigand P, Grupp K, Kluth M, Steurer S, et al. $\beta$ III-tubulin overexpression is an independent predictor of prostate cancer progression tightly linked to ERG fusion status and PTEN deletion. Am J Pathol 2014;184:609-17.

44. Galletti G, Matov A, Beltran H, Fontugne J, Miguel Mosquera J, et al. ERG induces taxane resistance in castration-resistant prostate cancer. Nat Commun 2014;5:5548.

45. Shao L, Kahraman N, Yan G, Wang J, Ozpolat B, et al. Targeting the TMPRSS2/ERG fusion mRNA using liposomal nanovectors enhances docetaxel treatment in prostate cancer. Prostate 2020;80:65-73.

46. Reig O, Marin-Aguilera M, Carrera G, Jimenez N, Pare L, et al. TMPRSS2-ERG in blood and docetaxel resistance in metastatic castration-resistant prostate cancer. Eur Urol 2016;70:709-13.

47. Marin-Aguilera M, Reig O, Mila-Guasch M, Font A, Domenech M, et al. The influence of treatment sequence in the prognostic value of TMPRSS2-ERG as biomarker of taxane resistance in castration-resistant prostate cancer. Int J Cancer 2019;145:1970-81.

48. Sánchez C, Mendoza P, Contreras HR, Vergara J, McCubrey JA, et al. Expression of multidrug resistance proteins in prostate cancer is related with cell sensitivity to chemotherapeutic drugs. Prostate 2009;69:1448-59.

49. Sánchez C, Mercado A, Contreras HR, Mendoza P, Cabezas J, et al. Chemotherapy sensitivity recovery of prostate cancer cells by functional inhibition and knock down of multidrug resistance proteins. Prostate 2011;71:1810-7.

50. de Morrée E, van Soest R, Aghai A, de Ridder C, de Bruijn P, et al. Understanding taxanes in prostate cancer; importance of intratumoral drug accumulation. Prostate 2016;76:927-36.

51. Wang B, Dukarevich M, Sun EI, Yen MR, Saier MH Jr. Membrane porters of ATP-binding cassette transport systems are polyphyletic. J Membr Biol 2009;231:1-10.

52. Davidson AL, Dassa E, Orelle C, Chen J. Structure, function, and evolution of bacterial ATP-binding cassette systems. Microbiol Mol Biol Rev 2008;72:317-64.

53. Martin SK, Kyprianou N. Exploitation of the androgen receptor to overcome taxane resistance in advanced prostate cancer. Adv Cancer Res 2015;127:123-58.

54. Sissung TM, Baum CE, Deeken J, Price DK, Aragon-Ching J, et al. ABCB1 genetic variation influences the toxicity and clinical outcome of patients with androgen-independent prostate cancer treated with docetaxel. Clin Cancer Res 2008;14:4543-9.

55. Lombard AP, Liu C, Armstrong CM, Cucchiara V, Gu X, et al. ABCB1 mediates cabazitaxel-docetaxel cross-resistance in advanced prostate cancer. Mol Cancer Ther 2017;16:2257-66.

56. Wang Y, Huang Z, Chen CZ, Liu C, Evans CP, et al. Therapeutic targeting of MDR1 expression by ROR $\gamma$ antagonists resensitizes crossresistant CRPC to taxane via coordinated induction of cell death programs. Mol Cancer Ther 2020;19:364-74.

57. Kato T, Mizutani K, Kameyama K, Kawakami K, Fujita Y, et al. Serum exosomal P-glycoprotein is a potential marker to diagnose docetaxel resistance and select a taxoid for patients with prostate cancer. Urol Oncol 2015;33:385.e15-20.

58. Hagenbuch B, Meier PJ. Organic anion transporting polypeptides of the OATP/ SLC21 family: phylogenetic classification as OATP/ SLCO superfamily, new nomenclature and molecular/functional properties. Pflugers Arch 2004;447:653-65.

59. Smith NF, Acharya MR, Desai N, Figg WD, Sparreboom A. Identification of OATP1B3 as a high-affinity hepatocellular transporter of paclitaxel. Cancer Biol Ther 2005;4:815-8.

60. de Morrée ES, Böttcher R, van Soest RJ, Aghai A, de Ridder CM, et al. Loss of SLCO1B3 drives taxane resistance in prostate cancer. Br J Cancer 2016;115:674-81.

61. Pressler H, Sissung TM, Venzon D, Price DK, Figg WD. Expression of OATP family members in hormone-related cancers: potential markers of progression. PLoS One 2011;6:e20372.

62. Alsinnawi M, Zhang A, Bianchi-Frias D, Burns J, Cho E, et al. Association of prostate cancer SLCO gene expression with Gleason grade and alterations following androgen deprivation therapy. Prostate Cancer Prostatic Dis 2019;22:560-8.

63. Skvortsov S, Skvortsova, II, Tang DG, Dubrovska A. Concise review: prostate cancer stem cells: current understanding. Stem Cells 2018;36:1457-74.

64. Castillo V, Valenzuela R, Huidobro C, Contreras HR, Castellon EA. Functional characteristics of cancer stem cells and their role in drug resistance of prostate cancer. Int J Oncol 2014;45:985-94.

65. Collins AT, Berry PA, Hyde C, Stower MJ, Maitland NJ. Prospective identification of tumorigenic prostate cancer stem cells. Cancer Res 2005;65:10946-51.

66. Burger PE, Gupta R, Xiong X, Ontiveros CS, Salm SN, et al. High aldehyde dehydrogenase activity: a novel functional marker of murine prostate stem/progenitor cells. Stem Cells 2009;27:2220-8.

67. van den Hoogen C, van der Horst G, Cheung H, Buijs JT, Lippitt JM, et al. High aldehyde dehydrogenase activity identifies tumorinitiating and metastasis-initiating cells in human prostate cancer. Cancer Res 2010;70:5163-73.

68. Castellón EA, Valenzuela R, Lillo J, Castillo V, Contreras HR, et al. Molecular signature of cancer stem cells isolated from prostate carcinoma and expression of stem markers in different Gleason grades and metastasis. Biol Res 2012;45:297-305.

69. Lai CJ, Lin CY, Liao WY, Hour TC, Wang HD, et al. CD44 promotes migration and invasion of docetaxel-resistant prostate cancer cells likely via induction of Hippo-Yap signaling. Cells 2019;8:295.

70. Marin-Aguilera M, Codony-Servat J, Reig O, Lozano JJ, Fernandez PL, et al. Epithelial-to-mesenchymal transition mediates docetaxel resistance and high risk of relapse in prostate cancer. Mol Cancer Ther 2014;13:1270-84.

71. Domingo-Domenech J, Vidal SJ, Rodriguez-Bravo V, Castillo-Martin M, Quinn SA, et al. Suppression of acquired docetaxel resistance in prostate cancer through depletion of notch- and hedgehog-dependent tumor-initiating cells. Cancer Cell 2012;22:373-88. 
72. Mittal K, Donthamsetty S, Kaur R, Yang C, Gupta MV, et al. Multinucleated polyploidy drives resistance to Docetaxel chemotherapy in prostate cancer. Br J Cancer 2017;116:1186-94.

73. Salem O, Hansen CG. The hippo pathway in prostate cancer. Cells 2019;8:370.

74. Gruber M, Handle F, Culig Z. The stem cell inhibitor salinomycin decreases colony formation potential and tumor-initiating population in docetaxel-sensitive and docetaxel-resistant prostate cancer cells. Prostate 2020;80:267-73. DOI: 10.1002/pros.23940.

75. Trerotola M, Rathore S, Goel HL, Li J, Alberti S, et al. CD133, Trop-2 and alpha2beta1 integrin surface receptors as markers of putative human prostate cancer stem cells. Am J Transl Res 2010;2:135-44.

76. Kanwal R, Shukla S, Walker E, Gupta S. Acquisition of tumorigenic potential and therapeutic resistance in CD133+ subpopulation of prostate cancer cells exhibiting stem-cell like characteristics. Cancer Lett 2018;430:25-33.

77. Tan H, Hou N, Liu Y, Liu B, Cao W, et al. CD133 antibody targeted delivery of gold nanostars loading IR820 and docetaxel for multimodal imaging and near-infrared photodynamic/photothermal/chemotherapy against castration resistant prostate cancer. Nanomedicine 2020;27:102192.

78. Carceles-Cordon M, Kelly WK, Gomella L, Knudsen KE, Rodriguez-Bravo V, et al. Cellular rewiring in lethal prostate cancer: the architect of drug resistance. Nat Rev Urol 2020;17:292-307.

79. Qiu S, Deng L, Bao Y, Jin K, Tu X, et al. Reversal of docetaxel resistance in prostate cancer by Notch signaling inhibition. Anticancer Drugs 2018;29:871-9.

80. Liu C, Li Z, Bi L, Li K, Zhou B, et al. NOTCH1 signaling promotes chemoresistance via regulating ABCC1 expression in prostate cancer stem cells. Mol Cell Biochem 2014;393:265-70.

81. Mimeault M, Johansson SL, Vankatraman G, Moore E, Henichart JP, et al. Combined targeting of epidermal growth factor receptor and hedgehog signaling by gefitinib and cyclopamine cooperatively improves the cytotoxic effects of docetaxel on metastatic prostate cancer cells. Mol Cancer Ther 2007;6:967-78.

82. Mimeault M, Johansson SL, Henichart JP, Depreux P, Batra SK. Cytotoxic effects induced by docetaxel, gefitinib, and cyclopamine on side population and nonside population cell fractions from human invasive prostate cancer cells. Mol Cancer Ther 2010;9:617-30.

83. Cui D, Dai J, Keller JM, Mizokami A, Xia S, et al. Notch pathway inhibition using PF-03084014, a $\gamma$-secretase inhibitor (GSI), enhances the antitumor effect of docetaxel in prostate cancer. Clin Cancer Res 2015;21:4619-29.

84. Mimeault M, Rachagani S, Muniyan S, Seshacharyulu P, Johansson SL, et al. Inhibition of hedgehog signaling improves the anticarcinogenic effects of docetaxel in prostate cancer. Oncotarget 2015;6:3887-903.

85. Rath O, Kozielski F. Kinesins and cancer. Nat Rev Cancer 2012;12:527-39.

86. Vale RD. The molecular motor toolbox for intracellular transport. Cell 2003;112:467-80.

87. Kapitein LC, Peterman EJ, Kwok BH, Kim JH, Kapoor TM, et al. The bipolar mitotic kinesin Eg5 moves on both microtubules that it crosslinks. Nature 2005;435:114-8.

88. Beer TM, Goldman B, Synold TW, Ryan CW, Vasist LS, et al. Southwest Oncology Group phase II study of ispinesib in androgenindependent prostate cancer previously treated with taxanes. Clin Genitourin Cancer 2008;6:103-9.

89. Wiltshire C, Singh BL, Stockley J, Fleming J, Doyle B, et al. Docetaxel-resistant prostate cancer cells remain sensitive to S-trityl-Lcysteine-mediated Eg5 inhibition. Mol Cancer Ther 2010;9:1730-9.

90. Kwon M, Godinho SA, Chandhok NS, Ganem NJ, Azioune A, et al. Mechanisms to suppress multipolar divisions in cancer cells with extra centrosomes. Genes Dev 2008;22:2189-203.

91. Sekino Y, Oue N, Shigematsu Y, Ishikawa A, Sakamoto N, et al. KIFC1 induces resistance to docetaxel and is associated with survival of patients with prostate cancer. Urol Oncol 2017;35:31.e13-20.

92. Sekino Y, Oue N, Koike Y, Shigematsu Y, Sakamoto N, et al. KIFC1 inhibitor CW069 induces apoptosis and reverses resistance to docetaxel in prostate cancer. J Clin Med 2019;8:225.

93. Yang J, Nie J, Ma X, Wei Y, Peng Y, et al. Targeting PI3K in cancer: mechanisms and advances in clinical trials. Mol Cancer 2019;18:26.

94. Malik SN, Brattain M, Ghosh PM, Troyer DA, Prihoda T, et al. Immunohistochemical demonstration of phospho-Akt in high Gleason grade prostate cancer. Clin Cancer Res 2002;8:1168-71.

95. Carver BS, Chapinski C, Wongvipat J, Hieronymus H, Chen Y, et al. Reciprocal feedback regulation of PI3K and androgen receptor signaling in PTEN-deficient prostate cancer. Cancer Cell 2011;19:575-86.

96. Kosaka T, Miyajima A, Shirotake S, Suzuki E, Kikuchi E, et al. Long-term androgen ablation and docetaxel up-regulate phosphorylated Akt in castration resistant prostate cancer. J Urol 2011;185:2376-81.

97. Yasumizu Y, Miyajima A, Kosaka T, Miyazaki Y, Kikuchi E, et al. Dual PI3K/mTOR inhibitor NVP-BEZ235 sensitizes docetaxel in castration resistant prostate cancer. J Urol 2014;191:227-34.

98. Davies BR, Greenwood H, Dudley P, Crafter C, Yu DH, et al. Preclinical pharmacology of AZD5363, an inhibitor of AKT: pharmacodynamics, antitumor activity, and correlation of monotherapy activity with genetic background. Mol Cancer Ther 2012;11:873-87.

99. Crabb SJ, Birtle AJ, Martin K, Downs N, Ratcliffe I, et al. ProCAID: a phase I clinical trial to combine the AKT inhibitor AZD5363 with docetaxel and prednisolone chemotherapy for metastatic castration resistant prostate cancer. Invest New Drugs 2017;35:599-607.

100. Gorin MA, Verdone JE, van der Toom E, Bivalacqua TJ, Allaf ME, et al. Circulating tumour cells as biomarkers of prostate, bladder, and kidney cancer. Nat Rev Urol 2017;14:90-7.

101. Iacovelli R, Ciccarese C, Schinzari G, Rossi E, Maiorano BA, et al. Biomarkers of response to advanced prostate cancer therapy. Expert Rev Mol Diagn 2020;20:195-205.

102. Goldkorn A, Ely B, Quinn DI, Tangen CM, Fink LM, et al. Circulating tumor cell counts are prognostic of overall survival in SWOG 
S0421: a phase III trial of docetaxel with or without atrasentan for metastatic castration-resistant prostate cancer. J Clin Oncol 2014;32:1136-42.

103. Vogelzang NJ, Fizazi K, Burke JM, De Wit R, Bellmunt J, et al. Circulating tumor cells in a Phase 3 study of docetaxel and prednisone with or without lenalidomide in metastatic castration-resistant prostate cancer. Eur Urol 2017;71:168-71.

104. Underhill HR, Kitzman JO, Hellwig S, Welker NC, Daza R, et al. Fragment length of circulating tumor DNA. PLoS Genet 2016;12:e1006162.

105. Kienel A, Porres D, Heidenreich A, Pfister D. cfDNA as a prognostic marker of response to taxane based chemotherapy in patients with prostate cancer. J Urol 2015;194:966-71.

106. Mehra N, Dolling D, Sumanasuriya S, Christova R, Pope L, et al. Plasma cell-free DNA concentration and outcomes from taxane therapy in metastatic castration-resistant prostate cancer from two phase III trials (FIRSTANA and PROSELICA). European Urology 2018;74:283-91. 